\title{
A methodology for the classification of gravel beaches
}

\author{
Y. Villacampa ${ }^{1}$, L. Aragones ${ }^{2}$, J. F. Serra ${ }^{3}$, \\ F. J. Navarro-González ${ }^{1} \&$ I. López ${ }^{2}$ \\ ${ }^{1}$ Department of Applied Mathematics, Alicante University, Spain \\ ${ }^{2}$ Department of Civil Engineering, Alicante University, Spain \\ ${ }^{3}$ Department of Transportation, \\ Polytechnic University of Valencia, Spain
}

\begin{abstract}
Beaches are highly flexible structures that can be deformed by several reasons, some natural as wind and swell and others not, as human actions. Gravel, considered as a component of the beach is not always separated from the rest of the materials. It is a part of the coastline sedimentary balance, usually with time and spatial scales much greater than those corresponding to the stretch of the coast under study. The conceptual and experimental difficulties of studying this kind of beach have meant that nowadays they are really unknown.

In this paper, methodologies to classify and determinate the most important characteristics in gravel beaches are presented. The authors have studied 34 shingle beaches in the region of Alicante (Spain) from a database with their characteristics. Obtained data corresponds to the morphology of the beach, the materials that take part in its composition and the wave energy, considering its incidence, the wave height, the local period and its influence on the coastline.

At the beginning, mathematical models are generated, allowing the expression of the relationships between the slope of berm and the rest of variables.

To classify the beaches, a factor analysis has been used on the experimental data matrix, considering all the variables as predictive, obtaining in this way an index for beach classification with similar characteristics. Furthermore, to determine the predictive variables that allow characterizing the 34 beaches, a discriminant analysis has been applied over several sets of variables. In each case, a predictive model of cluster belonging is created, considering a
\end{abstract}


discriminant function, and with the clustering function formed by different clusters.

The methodologies developed in this paper will be applied later to other beaches as classification and variable selection methods.

Keywords: mathematical model, gravel beaches.

\section{Introduction}

Gravel beaches are of great importance in the preservation of coastal communities with their environmental and agricultural resources [1]. As in the case of sand, gravel beaches act as a barrier protecting zones of soft cliffs. The porous structure of gravel and its hydraulic roughness dissipates the energy of the wave and reduce the damages in the coastal areas. Nevertheless, the study of this class of beaches is complex, and the scientific works are few compared with those focused on sand beaches [2].

In the coast of Alicante, there are 115 beaches, with 34 composed by gravel, that is, $29.56 \%$ of the total number. For this reason, it is very important this kind of studies from the economic and social points of view. These studies allow to avoid and estimate risks as erosion and flood. Other important result is the study of coast regeneration, because in some parts of the coast the lack of new sediments coming from rivers and gorges results in regressive effects in the coast. The knowledge of the equilibrium profile, and so, the volume of material needed in its regeneration is of great importance. The absence of this kind of studies is the reason to use other empirical approaches, [3, 4], obtained from laboratory results. However, the main problem of these formulations is that are based on geometric considerations regardless of the morphology and the wave energy and variability. A first step is to understand the limits of these approaches. Together with the availability of new numerical methods, improvements in the field of measuring techniques, the new geographical information systems (GIS) with improvements in the 3-dimensional compression, the study of these beaches can be enhanced.

In these beaches there are different proportions of each component [5], and this proportions change in each part of the beach. So, there are authors like [6] that do a classification using relative proportions and the sand distribution in the beach front and the backshore, obtaining several classes: a) Pure gravel beaches; b) Beaches with sand in the tide area and gravel in the backshore; and c) Mixed beaches with sand and gravel without zonal differentiation.

All the differences caused by the possible combinations of relative proportions and positions in a beach cause that the characteristics of the shore breaker zone are also different in each classified beach. So, when the principal component in the active zone is gravel, the shore breaker zone is smaller than in the case of having the sand as main component, and the wave breaks almost in the shore. As the most part of morphological changes occur in the foreshore area, in these beaches the sedimentary movement is shorter than in beaches that have sand in the active zone [7]. 
Storms in gravel beaches create a berm, giving a greater slope to the beach, and causing a shorter wave break zone and a reflection of a part of the wave energy. When a mix of sand and gravel is presented, the bigger components move over the smaller, with a separation that takes the big close to the shore [5, $8,9]$. For this reason, factors as the environment and the physical processes knowledge, the sediment characteristics and the flow changes are of great importance in the morph dynamic of these beaches.

The main objective of this study is to obtain a function to classify the beach type according to the previously visual classification. To obtain the function, a variable (slope of berm) is studied as dependent of 18 predictor variables. Also, a cluster analysis has been done to determine if the classification can be obtained from the variables used in the study.

The preliminary visual classification of the beaches is:

(1) Sand and gravel beaches.

(2) Sand and separated thin gravel beaches.

(3) Sand and separated big gravel beaches.

(4) Pure gravel beaches.

\section{Studied area}

Alicante is in the south-east of Spain. It has a total coastal length of $244 \mathrm{Km}$, and can be morphologically divided in two zones:

1. From the south limit to Cape Las Huertas, with sand beaches.

2. From Cape Las Huertas to the north limit, where gravel beaches are predominant.
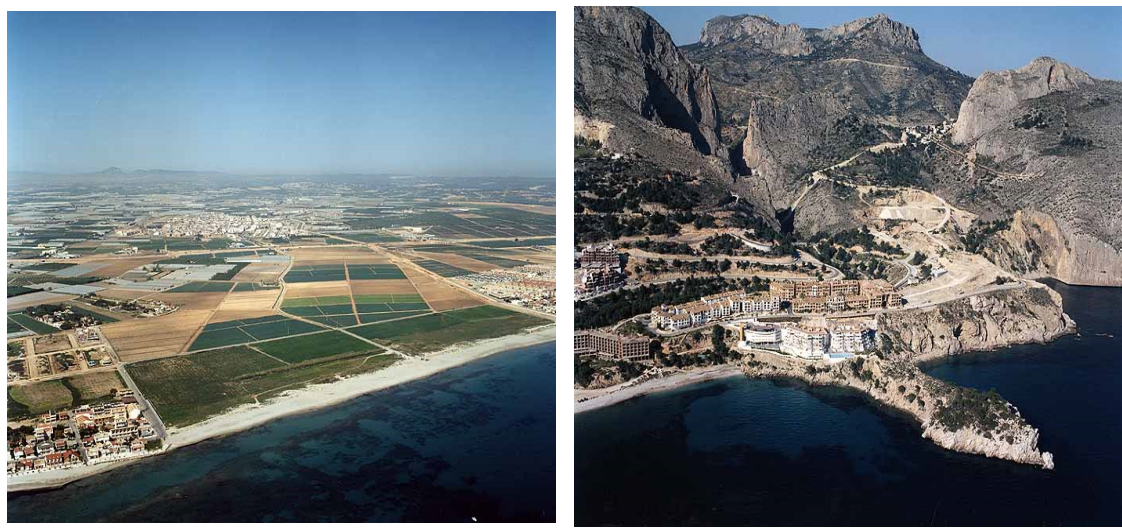

Figure 1: South (left) and north (right) coast of Alicante. Photo by the authors.

In the second area, while the southern part has small cliffs with gravel and loam, in the north there are limestone cliffs. 
The orientation of the beaches makes them affected by swells from southsouth-east to north-east. It is a microtide zone with amplitudes of $0.25 \mathrm{~m}$. for the astronomical and $0.53 \mathrm{~m}$. for the meteorological tides.

Also, two zones can be differentiated:

- Southern limit - Cape La Nao: E as most frequent swell and NE as the strongest.

- $\quad$ Cape La Nao - Northern limit: ENE as most frequent swell and NE as the strongest.

Active beach is characterized by a backshore with crests of berm formed by the strongest swells in each beach. Given the diversity of orientations and swells, and the diversity of material supply, there is a great diversity of sedimentary topology. From gravel to sand with several proportions in the combinations of both sediments. The most part of them share a gravel backshore.

\section{Goals and tools}

The main objective of this paper is to obtain information parameters, allowing the knowledge and classification of gravel beaches using experimental data containing its characteristics. A first approach is done using data from 34 beaches in the coast of Alicante. The data set is composed of 18 variables.

In this paper the study and classification of beaches is done using multivariate analysis techniques as linear regression models, numerical models, factorial analysis and discriminant analysis.

The mathematical models have been obtained considering the variable 'Slope of Berm' as dependent variable, using as independents: 'Average size: D50Weight', 'Wave height: H', 'Period: T', 'Beach width', 'Gorge-river', 'Berm height', 'Berm width' and 'Iribarren index'. Linear models as in $[10,11]$ and numerical models using the methodology introduced in [12-14] have been used improving the results obtained in the linear approximation. A factorial analysis allows to define a classification index over the characteristics of the beaches. Finally, the use of discriminant analysis allows to define a function to determine the class of beach using the values of the variables.

\section{Methodology}

In the north of Alicante 34 gravel beaches have been considered. A multivariate analysis has been applied to the data and some relationships have been established using linear regression and numerical models. These models give equations or numerical values to estimate the results in any other conditions. Also the results of a factorial and a discriminant analysis allow to define indexes to classify and determine the character of each beach. 


\subsection{Analysis of the variables that determines the characterization of the beaches}

A dataset containing the variables with relevance for the study has been obtained for 34 beaches. Previously 19 variables have been considered in each beach. The numerical value of each variable has been assigned considering a pre-established scale. The considered variable are: X1: Average size, D50 (weight); X2: wave height, H; X3: period, T; X4: Profile type; X5: Beach width; X6: Beach length; X7: Unimodal-Bimodal; X8: Gorge-River; X9: Berm height; X10: Berm width; X11: concavity coefficient $(\mathrm{Cc})$; X12: \% holes; X13: apparent density; X14: Break Iribarren number with slope of berm; X15: Sorting (So); X16: Skewness (Sk); X17: Kurtosis (K); X18: Uniformity coefficient (Cu); X19: Slope of berm. From this dataset the variables to use in the study were selected.

\subsection{Regression and numerical models}

In the study of linear models the considered dependent variable has been the slope of berm that is one morphodynamic characteristic of this kind of beaches [15] and presents dependence with the characteristic of the dry sediment (Foreshore) and the wave's energy, that is related with the independent variables.

A possibility is to consider all the variables and calculate the linear regression. This result can be compared with other regressions calculated ignoring some of the variables. Using model selection criteria the simplest model can be selected. In this study the backward selection method has been used with the statistical software SSPS [10]. The selected model has a fitness coefficient $\mathrm{R}^{2}$ near 0.7 . The model with the smallest number of independent variables is:

$$
\begin{aligned}
& X_{19}=-7.763 E-16+0.281 X_{1}+0.166 X_{2}+0.155 X_{5}-0.34 X_{7}+ \\
& +0.435 X_{8}+0.408 X_{9}-0.623 X_{10}-0.335 X_{11}+0.160 X_{12}-0.240 X_{13}+ \\
& +0.93 X_{14}-0.375 X_{15}
\end{aligned}
$$

The fitness is $\mathrm{R}^{2}=0.707$.

The linear regression model does not have a good fitness for the variable 'slope of berm', and the authors have considered the use of the numerical methodology developed in $[12,13]$, and a reduction in the number of independent variables considered from 18 to 8: D50Weight, H, T, Beach width, Gorge-River, Berm height, Berm width and Iribarren index. This selection takes into account that some variables as the slope of the beach and the wave height are included in the calculation of the Iribarren index, and could appear a bias in the results. Also, the average size D50 is related with the variables Sorting, Skewness, Kurtosis, \% holes and the uniformity coefficient.

\subsection{Numerical model}

In the calculation of a numerical model using the methodology introduced in [12, 13] has been used 8 variables: D50Weight, H, T, Beach width, Gorge-River, Berm height, Berm width, Iribarren number, and as dependent variable the slope 
of berm. The methodology estimates the value of the model in the 34 beaches using the independent variables. From a set of numerical models, the selected has a fitness of $\mathrm{R}^{2}=0.93$ and an average error of 0.071 . The figure 2 shows the experimental and the estimated values:

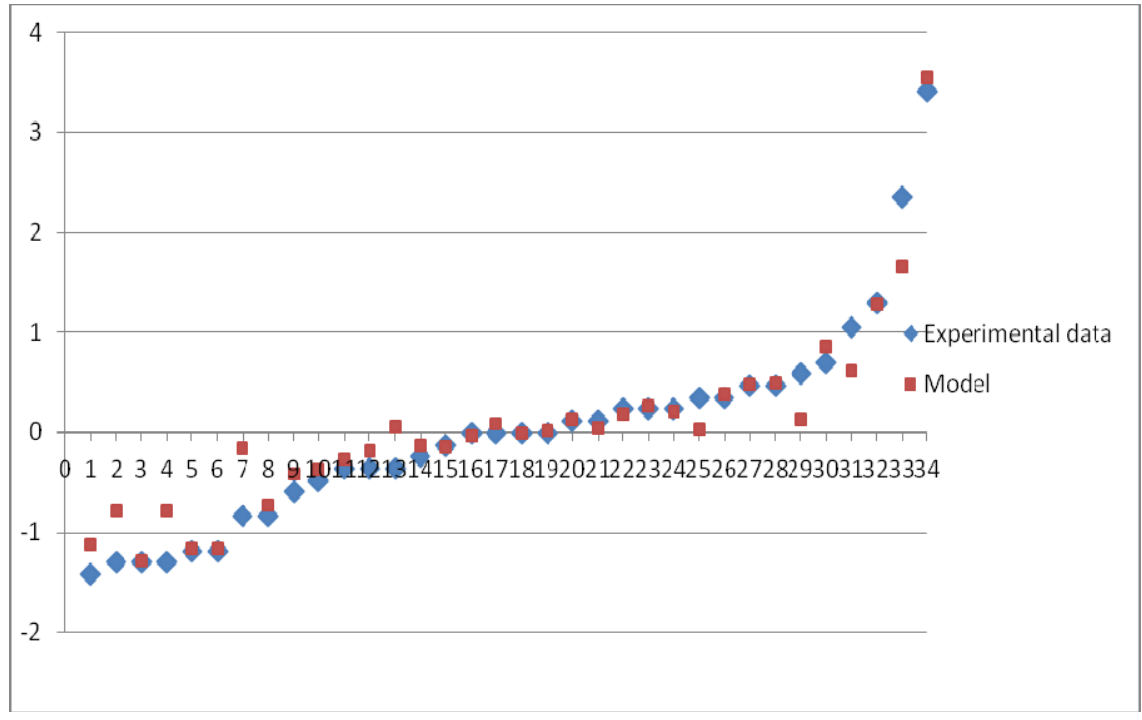

Figure 2: Numerical model.

The stability of the model is studied using a Montecarlo simulation, considering random perturbations of the experimental points, and calculating the models in these perturbed points. As can be seen in the figure 3 , for values of the modifications smaller than $20 \%$, the calculated model changes less than $5 \%$, that is, the model is stable.

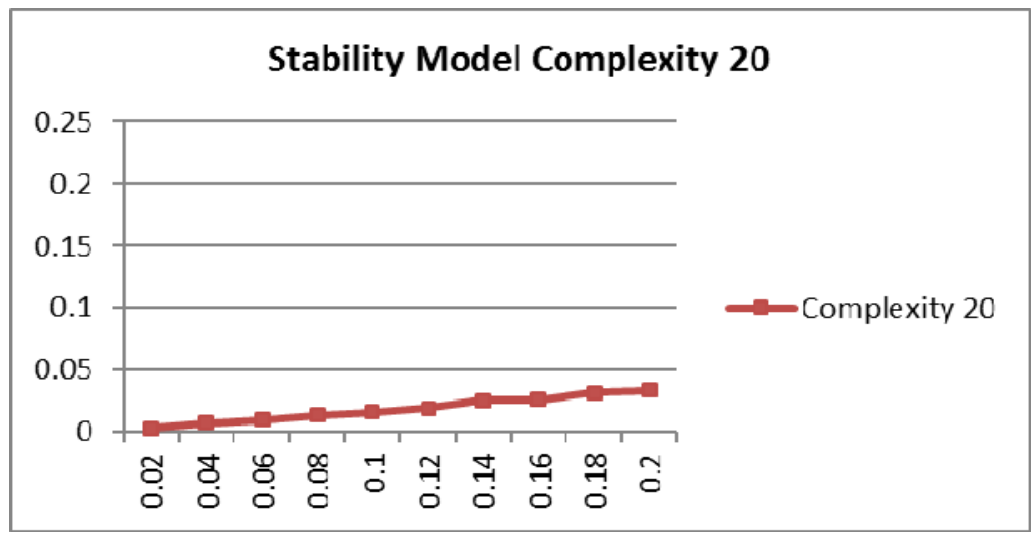

Figure 3: The stability of the model. 


\subsection{Classification in homogeneous zones according to the characteristics of gravel beaches}

A factorial analysis over the experimental constructed data matrix has been made considering 18 variables, obtaining a new variable that allows to define an index reflecting the homogeneity of gravel beaches when considering their characteristics. This index allows analysing the differences between the beaches, and grouping them in clusters. In this paper the index is constructed using the first factor components as are defined in [16] with an expression:

$$
I N D G_{1}=\sum_{i=1}^{18} a_{i 1} X_{i}
$$

where $a_{i 1}$ are the components of the first factor and represent the relative weight of each variable to the index.

This new variable can take positive and negative values. For a better representation of the difference between groups an exponential transform has been done. This kind of transform is defined in [17] for values in the interval $[0,100]$. To do this, it is enough to apply the function defined for the values of $I N D G_{1}$ :

$$
\begin{aligned}
& \text { if } I N D G_{1}<0, F\left(I N D G_{1}\right)=1+(99 / 2) e^{I N D G_{1}} ; \\
& \text { if } I N D G_{1} \geq 0 \quad F\left(I N D G_{1}\right)=100-(99 / 2) e^{-I N D G_{1}}
\end{aligned}
$$

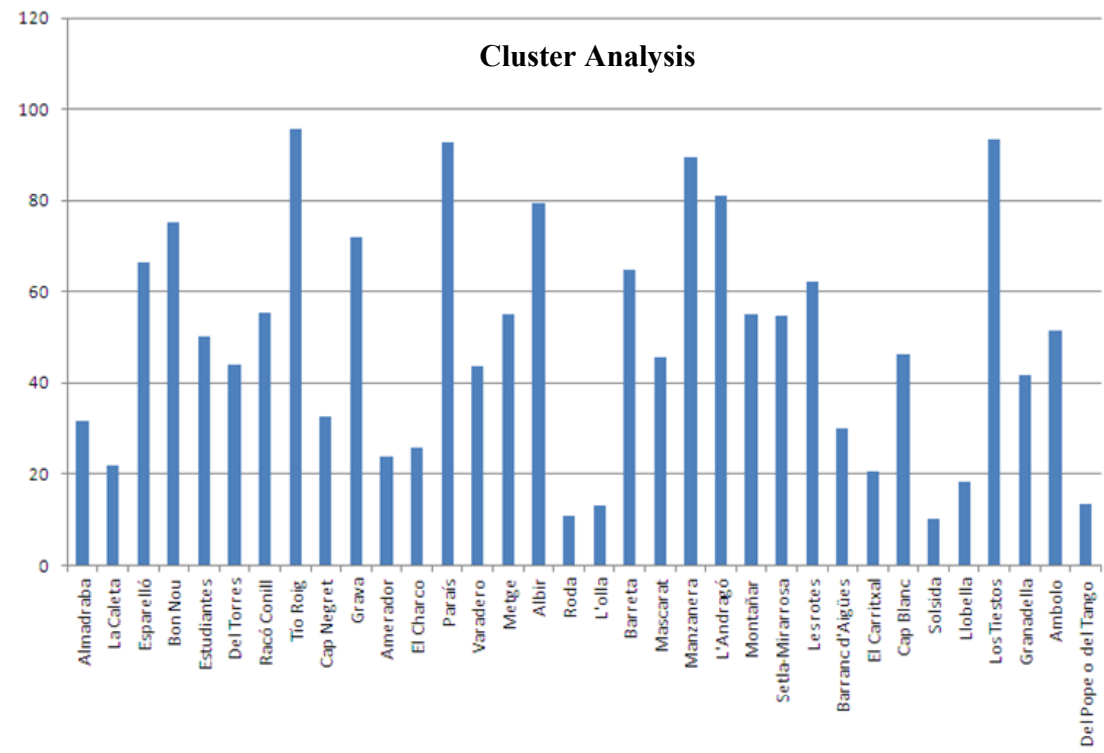

Figure 4: Index reflecting the homogeneity of gravel beaches. 
The defined index F (INDG1) is useful to study the differences between beaches when considering the experimental values of the predictive variables. Clusters with similar beaches can be observed together with others that have very different characteristics.

\subsection{Classification using a discriminant analysis}

Using a discriminant analysis, a predictive model has been obtained for the determination of the beach class, considering the variable beach typology as clustering variable, and corresponding to a previous classification of the beaches in four clusters. The discriminant function uses a linear combination of the 18 predictive variables, obtained using the software SSPS. The discriminant function explain $87.3 \%$ of the variance:

$$
\begin{gathered}
\mathrm{FD}=-12.623-0.458 \times 1-0.526 \times 2-0.811 \times 3+1.269 \times 4+0.249 \\
\mathrm{X} 5+0.653 \times 6-0.830 \times 7-0.280 \times 8+1.267 \times 9-3.059 \times 10+4.260 \\
\mathrm{X} 11-0.886 \times 12+1.715 \times 13-0.968 \times 14+3.944 \times 15+2.012 \\
\mathrm{X} 16-0.481 \mathrm{X} 17-3.127 \mathrm{X} 18+0.941 \mathrm{X} 19
\end{gathered}
$$

The FD function gives the correct classification for all the beaches except Granadella. The discriminant classifies it as mixed gravel and sand beach against the initial classification as gravel beach.

Using the proposed discriminant function, each beach is characterized by an interval $\left\{I_{i}\right\}_{i=1}^{4}$ that determines the kind of beach. The obtained intervals for the discriminant function are:

$$
I_{4}=[-5.806-2.806] ; I_{2}=\left[\begin{array}{ll}
-3.758-1.348
\end{array}\right] ; I_{3}=\left[\begin{array}{ll}
0.116 & 3.114
\end{array}\right] I_{1}=\left[\begin{array}{ll}
3.75 & 7.02
\end{array}\right]
$$

Intervals $I_{4}$ and $I_{2}$ intersects, so there are beaches as Granadella that are classified in class 2 and class 4 .

This introduces a difference between the previous visual inspection of the Granadella beach and the result of the discriminant analysis. The reason of this difference is the great diversity between the values of the variable average size D50 between the backshore and the stram, which classify as class 2 a beach previously considered of class 4 . That shows that there are variables as D50 that have great impact in the classification. In future researches will be of interest enhance the set of predictive variables.

\section{Conclusions}

This paper introduces new methodologies to analyse and classify gravel beaches in the Alicante coastal zone (Spain). These methods can also be used in other beaches.

Several models have been developed to model the variable 'slope of berm'. An initial model was obtained using backward linear regression techniques with a fitness of 0.7. Also, a numerical methodology was used, obtaining stable 
models with a better fitness. These models estimate the 'slope of berm' as a function of other predictive variables.

Using a factorial and a discriminant analysis the beaches have been grouped in four clusters, and an index, calculated from the components of the first factor, has been obtained to classify the beaches.

A classification of the gravel beaches in Alicante has been done using discriminant analysis, obtaining as a result a function to classify them from the values of the 18 predictive variables. The values of this discriminant function allow to define classification intervals. The function results of great precision in the determination of the kind of beach using the variables analysed in this work.

In future researches, the authors will analyse the important of other variables to improve the mathematical models and the classification function presented in this paper. Also, the use of normalized values for some variables, as the sediment average size D50 will be studied, to improve the stability of the obtained functions.

\section{References}

[1] Mason, T. and Coates, T.T. (2001) Sediment transport processes on mixed beaches: a review for shoreline management. J. Coast. Res., 17, pp. 645657.

[2] Buscombe, D., Masselink, G., 2006. Concepts in gravel beach dynamics. Earth-Sci. Rev. 79 (1-2), pp. 33-52.

[3] Powell, K.A., 1990. Predicting short term profile response for shingle beaches. SR Report 219, HR Wallingford, Wallingford.

[4] Van der Meer, J., 1988. Rock slopes and gravel beaches under wave attack. Delft University of Technology, Delft, The Netherlands.

[5] Orford, J.D., Carter, R.W.G., Jennings, S.C., Hinton, A.C., 1995. Processes and time scales by which a coastal gravel dominated barrier respond geomorphologically to sea level rise-Story Head Barrier, NovaScotia. Earth Surf. Processes Landf. 20 (1), pp. 21-37.

[6] Pye, K. (2001) The nature and geomorphology of coastal shingle. In: Ecology and Geomorphology of Coastal Shingle (Eds J.R. Packham, R.E. Randall, R.S.K. Barnes and A. Neal), pp. 2-22. Westbury Academic and Scientific, Yorkshire.

[7] Pedrozo-Acuña, A., Simmonds, D.J., Otta, A.K., Chadwick, A.J. (2006). On the cross-shore profile change of gravel beaches. Coastal Engineering 53 (2006), pp. 335-347.

[8] Everts, C.H., Eldon, C.D., Moore, J., 2002. Performance of cobble berms in Southern California. Shore Beach 4 (70), pp. 5-14.

[9] Osborne, P.D., 2005. Transport of gravel and cobble on a mixed-sediment inner bank shoreline of a large inlet, Grays Harbor, Washington. Mar. Geol. 224 (1-4), pp. 145-156.

[10] SPSS 9.0 Inc. Regression models. 1999.

[11] S-Plus 2000. Guide to statistics. Vol. 1, 2; Mathsoft, Inc. 1999. 
[12] Villacampa, Y.; Navarro-González, F.J.; Llorens, J. (2009). A geometric model for the generation of models defined in Complex Systems. 978-184564-194-8, pp. 71-82.

[13] Navarro-González, F.J. Y. Villacampa. A new methodology for complex systems using n-dimensional finite elements. Advances in Engineering Software 48 (2012), pp. 52-57.

[14] Navarro-González, F.J. Y. Villacampa. Generation of representation models for complex systems using Lagrangian functions. Advances in Engineering Software 64 (2013), pp. 33-37.

[15] Otvos, E.G. (2000) Beach ridges - definitions and significance. Geomorphology, 32, pp. 83-108.

[16] I. García- Lautre; C. Gil-Canaleta; P. Pascual-Arzoz \& M. Rapún Gárate. Una propuesta metodológica para la ordenación de las infraestructuras regionales. Estudios Regionales No 51, pp. 145-170. 1998.

[17] Calsamiglia, X 1990. La financiación de las Comunidades Autónomas y el principio de solidaridad. De Economía Pública, 6, pp. 3-43. 